(c) 2010 IEEE. Personal use of this material is permitted. Permission from IEEE must be obtained for all other uses, in any current or future media, including reprinting/republishing this material for advertising or promotional purposes, creating new collective works, for resale or redistribution to servers or lists, or reuse of any copyrighted component of this work in other works. 


\title{
Evaluating Relationship between Sexuality and Mental Health with the help of Computers
}

\author{
Marjan Khajehei, Maja Hadzic \\ Health Informatics Lab at the DEBII, Curtin University of Technology \\ marjan.khajehei@postgrad.curtin.edu.au,m.hadzic@curtin.edu.au
}

\begin{abstract}
Sexual dysfunction induces distress, strongly affects all aspects of life, and results in poor mental health. Preliminary research studies have provided some evidence on the relationship between sexuality and mental health. Nevertheless, a number of research issues are hindering effective progress in this research arena. Computer-based technologies could be applied to address the existing research issues and obtain new knowledge in the field. Applying advanced computerbased techniques such as data mining to analyze the collected data will help gain valuable knowledge. Such knowledge could be used in development of better sexual education programs, better counseling approaches and better therapies.
\end{abstract}

\section{Introduction}

Sexual health is defined by the World Health Organization (WHO), as "a state of physical, emotional, mental and social well-being in relation to sexuality; it is not merely the absence of disease, dysfunction or infirmity" [1].

It has also been shown that any deterioration in normal sexual functioning, and elements of the sexual response cycle, results in sexual dysfunction. The American Psychiatric Association specifies sexual dysfunction as "an inability to perform or reach an orgasm, painful sexual intercourse, a strong repulsion of sexual activity, or an exaggerated sexual response cycle or sexual interest" [2].

Sexual dysfunction is highly common in women and men, affecting about $43 \%$ of women and $31 \%$ of men [3]. This problem induces distress, strongly affects all aspects of life, and results in poor mental health. In addition, it significantly influences mood, self-esteem, interpersonal functioning, and overall life satisfaction. Studies have shown that poor mental health negatively affects women's sexuality and can be associated with risky sexual behavior [4]. Psychosocial factors such as quality of the partners' relationship, emotional distress, and social problems [5] significantly increase the occurrence and frequency of sexual difficulties. Moreover, psychiatric disorders, such as major depressive disorder, panic disorder, obsessive- compulsive disorder, anorexia nervosa, and schizophrenia can have important impacts on couples' ability to achieve satisfying sexual relationships [6].

Emotional problems and sexual dysfunction are known as important public health concerns. Therefore, individual's sexual needs must be taken into account, together with the critical contribution of psychosocial and contextual factors. The relationship between sexuality and mental health has to be studied to develop better educational approaches, counseling programs and therapies that are more suitable. In this article, we aim to review the literature in order to determine the relationship between sexuality and mental health, and identify the key factors affecting this relationship.

\section{Section 1: Relationship between Sexuality and Mental Health}

\subsection{Female's sexuality in literatures}

There has been a mutual relationship between females' sexuality and mental health in several studies.

\subsubsection{Sexuality in women aged $18-65$ years}

Sexual dissatisfaction has also been shown to be related to lower psychological well-being in women. Davison et al. [7] demonstrated that women who were more satisfied with their sexual life, had higher scores on the positive well-being. In addition, the psychological health status of women who were less satisfied with their sexuality was lower than that of satisfied women. Despite researchers having conceded that the relationship between sexual health and wellbeing was complex and many other factors might have contributed to this problem, they did not examine the role of demographic parameters, medication, emotional elements and partner's characteristics in the sexual satisfaction, well-being and their relationship. Moreover, many participants were excluded from the study because a minimal level of sexual activity of at least once per fortnight was needed to participate in the study, and this inclusion criterion might have prevented most of the elder participants from entering the study as they had probably had less sexual intercourse. 


\subsubsection{Sexuality in menopausal women:}

Danaci et al. [8] performed a study into the relationship between sexuality and psychological and hormonal features in 324 menopausal women. Findings of their study revealed that the menopausal state and hormonal changes did not affect the sexual behavior and psychological state of 40-60 year old women, but the increase in anxiety and depression scores affected the sexual life in a negative manner; although, the result of this research contradicted the fact that a decrease in sex hormones during menopausal years causes vaginal dryness, dyspareunia, lower sexual desire and sexual dissatisfaction [9].

Another study of the psychological status and sexuality in postmenopausal women carried out by Borissova et al. [10] demonstrated that the changes in sexuality were related to the declined estrogen activity, the influence of the psychosocial factors, the lack of a permanent intimate partner, and the derogatory attitude of the society towards the sexuality of postmenopausal women. The limitation of this research is that the study lacked information on the effect of medicines used by postmenopausal women on their sexuality and mental health.

\subsubsection{Sexuality in women experiencing depressive symptoms}

In another study conducted by Frohlich et al. in 2002 [11] depressive symptoms and sexual life of college women were evaluated. The results of the study revealed that women who suffered depressive symptoms had more desire for both sexual activity alone and masturbation. Nonetheless, depressed women showed more sexual problems such as less vaginal lubrication, less orgasm, more sexual pain and were less satisfied with their sexual life. There was, however, a contradiction between the results of this study with those of other studies, which confirmed that depressed women had less sexual desire. The researchers did not take into account the importance of the emotional well-being of the women, and also neglected the possibility that the reason why participants masturbated, but were not satisfied with their sexual life might have been the lack of emotional intimacy; as emotional needs cannot be met while masturbating. Moreover, they only included young women in their research, while the results might have been different if women of all ages had been included.

\subsubsection{Sexuality in women suffering anxiety disorders}

Vulink et al. [6] compared the sexual lives of female patients, referring to an outpatient clinic for Obsessive Compulsive Disorders (OCD), with a control group consisting of healthy women. They asserted that OCD patients reported more sexual disgust, less sexual desire, less sexual arousal and less satisfying orgasm. One of the shortcomings of this study, is that the partners' sexual functioning was not evaluated in this study as it could have had a significant impression on the women's sexuality [12]. Furthermore, in contrary to other studies in which the Serotonin Reuptake Inhibitors (SRIs) (Antidepressant medicines) influenced the sexuality of patients [13], Vulink et al. claimed that medicines used to treat patients suffering Obsessive Compulsive Disorder (including SRIs) did not affect their sexual life.

\subsection{Factors affecting male's sexuality}

Male sexual function has been shown to be impressed by many factors such as their mood status and mental health.

\subsubsection{Sexuality in ageing men}

Using Androgen Deficiency in the Ageing Men (ADAM) questionnaire, Lee et al. [14] evaluated the relationship between androgen deficiency symptoms with psychological factors, and quality of life in ageing men. They declared that age, duration of marriage, occupation, household income, and physical health were found to be significant factors affecting androgen deficiency status. In addition, men, who were recognised to suffer from androgen deficiency, had higher anxiety and depression scores, higher level of stress, and poorer physical and mental quality of life; although, the significant role of nationality was not considered [15]. Previous studies have shown that Japanese men, despite higher rate of erectile dysfunction and decreased libido, are more sexually satisfied in comparison to American men [16]. On the other hand, in this research, they used the ADAM questionnaire to evaluate the sexual dysfunction of male participants; however, therefore, the level of serum testosterone in patients should have been measured after obtaining ADAM scores in order for researchers to be able to put androgen deficiency label on patients.

\subsubsection{Sexuality in men suffering Erectile Dysfunction}

Another significant finding in the literature is that men who suffered erectile dysfunction (ED), rated themselves as significantly more depressed than those with normal erectile function in another study [17]. The results of the Shabsigh's study showed that 26 of 48 men with ED (54\%) reported depressive symptoms. Nonetheless, the association between depression and ED was found to be independent of age. In addition, the relationship between depression and ED was shown to be independent of the health status of individuals; while other studies' results have demonstrated that health status significantly affects sexuality and mental health of men [18]. Furthermore, the results of this study might have been partly unreliable due to the biased selection, as the sampling was not based on the random selection. 


\subsubsection{Sexuality in depressed men}

Turkistani [19] declared in their study that the most frequent types of sexual dysfunction among depressed men were unsound sexual interest and erectile dysfunction; however, ejaculatory dysfunction was the least associated with depression. Additionally, they showed that marital problems, medication, physical illness and the severity of depression were risk factors for sexual dysfunction associated with depression. However, the majority of participants in this study were from low-income and middle class families, and the researchers did not compare the role of lower income and higher income in inducing sexual dissatisfaction and mental problems. Moreover, in this study, the researcher interviewed patients in order to record their information. As it is well-known, patients who are interviewed face-to-face, are less likely to give correct answers to questions, especially when they have some psychological problem such as depression, and when it comes to some sensitive topics such as sexuality and marital difficulties. Therefore, we hypothesize that patients had not been truly cooperative.

\subsection{Sexuality in homosexuals}

Gays and lesbians are among those who suffer more sexual, social and psychological problems [20]. King et al. [21] compared homosexuals with heterosexual in terms of psychological status, quality of life and use of mental health services. They showed that gay men and lesbians experienced more psychological distress than heterosexual men and women did. In addition, homosexuals were more likely than heterosexual to live alone, consult mental health professionals, have suicidal thoughts, and use recreational drugs and alcohol.

\section{Section 2: Literature Review on Research Methodologies}

\subsection{Online questionnaires}

Advantages and disadvantages of online questionnaires have been discussed in the article written by Wright [22]. According to the context of this article, one of the advantages of conducting an online survey is that internet can provide access to people who are difficult to interview face-to-face. In addition, an online survey is a time-saving method to collect data from a large population. Moreover, an internet-based survey is a cost-effective method to set out a study that eliminates the need for paper and other costs, such as posting, printing, data entry and staff hire.

Regarding advantages of online questionnaires and computer-based surveys, this method has been used in many medical science studies, and has been shown to be one of the most reliable methods of data collection while collecting sensitive information. Russell et al. [23] benefitted from using this approach in their study. By means of computerized questionnaires, they were able to show the relationship between sexual orientation and suicidal thoughts and behaviours.

Kaestle et al. [24] used a computer-assisted selfinterviewing technology, and showed a strong association between initiation of sexual intercourse and sexually transmitted infection. They stated that using computer-based questionnaires could be very useful while asking about sensitive topics like sexuality. In addition, they believed that this technology improved privacy, and probably reduced nonresponse.

\subsection{Data mining}

While evaluation of mental health and sexuality has been a challenging research issue, several studies have been carried out to take advantage of the new analysing method such as data mining. In their study, Delen et al. [25] compared the two methods of analysing, Data mining and Logistic Regression, in order to develop prediction models for breast cancer survivability. They reported that data mining would be more accurate, sensitive and reliable method in medical research studies and its accuracy is more than that of logistic regression (most commonly used statistical method).

In addition, the relationship between antipsychotic drugs and cardiac disease, using data mining, was inspected in the study conducted by Coulter et al. [26]. The results of the study showed that data mining enabled researchers to find relationship between these two elements, and this method of analyzing has the potential to be used in studies investigating relationships.

\section{Future work}

In Table 1 we have highlighted a number of important research efforts in this research arena. Although previous research studies have evaluated factors influencing both sexuality and mental health in men and women, a large number of questions have remained unanswered, and there is a need to extend existing studies in the following ways:

\subsection{Identify and examine factors related to the complex phenomena of interest.}

\section{It is important to:}

1. Identify factors affecting mental health and sexuality of men and women;

2. Compare sexuality and mental health of the two sexes with regard to the various factors;

3. Identify the relationship between these factors. 
Table 1: A summary of the literature review.

\begin{tabular}{|c|c|c|c|c|c|}
\hline Author(s), year & Females & Males & Homosexuals & Data Analysis & Shortcoming \\
\hline $\begin{array}{c}\text { Davison et al. } \\
2009\end{array}$ & $\mathrm{~F}$ & -- & -- & $\begin{array}{l}\text {-Self-reporting } \\
\text { questionnaires. } \\
\text {-SPSS software. }\end{array}$ & $\begin{array}{l}\text {-Exclusion of many } \\
\text { participants. } \\
\text {-Ignorance of the role of } \\
\text { confounding factors. }\end{array}$ \\
\hline $\begin{array}{c}\text { Danaci et al. } \\
2003\end{array}$ & $\mathrm{~F}$ & -- & -- & $\begin{array}{l}\text {-Self-reporting } \\
\text { questionnaires. } \\
\text {-SPSS software. }\end{array}$ & $\begin{array}{l}\text {-Ignorance of the role of } \\
\text { hormones in menopausal } \\
\text { women. }\end{array}$ \\
\hline $\begin{array}{c}\text { Borissova et al. } \\
2001\end{array}$ & $\mathrm{~F}$ & -- & -- & $\begin{array}{c}\text {-Hormone } \\
\text { measurement. } \\
\text {-SPSS software. }\end{array}$ & $\begin{array}{l}\text {-Ignorance of the role of } \\
\text { confounding factors. }\end{array}$ \\
\hline $\begin{array}{l}\text { Frohlich et al. } \\
2002\end{array}$ & $\mathrm{~F}$ & - & -- & $\begin{array}{l}\text {-Self-reporting } \\
\text { questionnaires. } \\
\text {-SPSS software. }\end{array}$ & $\begin{array}{c}\text {-Ignorance of the partner's } \\
\text { role. }\end{array}$ \\
\hline $\begin{array}{l}\text { Vulink et al. } \\
2006\end{array}$ & $\mathrm{~F}$ & -- & -- & $\begin{array}{l}\text {-Self-reporting } \\
\text { questionnaires. } \\
\text {-SPSS software. }\end{array}$ & $\begin{array}{l}\text {-Including only young } \\
\text { women. } \\
\text {-Ignorance of the role of } \\
\text { passionate partner. }\end{array}$ \\
\hline $\begin{array}{l}\text { Lee et al. } \\
2009\end{array}$ & -- & $\mathrm{M}$ & - & $\begin{array}{l}\text {-Self-reporting } \\
\text { questionnaires. } \\
\text {-SPSS software. }\end{array}$ & $\begin{array}{c}\text {-Ignorance of the partner's } \\
\text { sexual function. } \\
\text {-Controversial results. }\end{array}$ \\
\hline $\begin{array}{c}\text { Shabsigh et al. } \\
1998\end{array}$ & -- & $\mathrm{M}$ & -- & $\begin{array}{c}\text {-Interview. } \\
\text {-SPSS software. }\end{array}$ & - Biased selection. \\
\hline $\begin{array}{c}\text { Turkistani } \\
2004\end{array}$ & -- & $\mathrm{M}$ & -- & $\begin{array}{c}\text {-Interview. } \\
\text {-SPSS software. }\end{array}$ & $\begin{array}{l}\text {-Biased data gathering } \\
\text { method. } \\
\text {-Controversial results. } \\
\text {-Biased selection. }\end{array}$ \\
\hline $\begin{array}{l}\text { King et al. } \\
\quad 2003\end{array}$ & $\mathrm{~F}$ & $\mathrm{M}$ & $\mathrm{H}$ & $\begin{array}{l}\text {-Self-reporting } \\
\text { questionnaires. } \\
\text {-SPSS software. }\end{array}$ & N/A \\
\hline $\begin{array}{l}\text { Russell et al. } \\
2001\end{array}$ & $\mathrm{~F}$ & M & $\mathrm{H}$ & $\begin{array}{l}\text { Computerized } \\
\text { questionnaires }\end{array}$ & $\mathrm{N} / \mathrm{A}$ \\
\hline $\begin{array}{c}\text { Kaestle et al. } \\
2005\end{array}$ & $\mathrm{~F}$ & -- & -- & $\begin{array}{l}\text { Computerized } \\
\text { questionnaires }\end{array}$ & N/A \\
\hline $\begin{array}{l}\text { Delen et al. } \\
2005\end{array}$ & $\mathrm{~F}$ & -- & - & $\begin{array}{l}\text { Comparing Data } \\
\text { mining and } \\
\text { Logistic } \\
\text { Regression. }\end{array}$ & $\mathrm{N} / \mathrm{A}$ \\
\hline $\begin{array}{c}\text { Coulter et al. } \\
2001\end{array}$ & $\mathrm{~F}$ & $\mathrm{M}$ & -- & Data mining & $\mathrm{N} / \mathrm{A}$ \\
\hline
\end{tabular}

\subsection{Identify and address gaps in the existing research}

There are some preliminary studies which could provide us with a a general view about the relationship between sexuality and mental health, and affecting factors in both men and women. However, there are some gaps (research areas that are missing reliable evidence) and some controversies in the existing research studies and therefore, further consolidating evidence is needed to increase the understanding of this topic.

\subsection{Design an integrated study that will evaluate all factors simultaneously}

An integrated study including all main factors should be conducted in order to produce reliable evidence, regarding the relationship between sexuality and mental health. Hence, the relationship between sexuality and mental health, and the associated factors, should be examined using an integrated approach that examines the factors and their affect simultaneously.

\subsection{Design a method that will enable collection of unbiased data}

Participants who are interviewed face-to-face are less likely to give correct answers to questions, especially when they have some psychological 
problem such as depression, and when it comes to some sensitive topics such as sexuality and marital difficulties. Therefore, different approaches such as online questionnaires should be used to facilitate collection of unbiased data.

\subsection{Incorporate powerful computer-based data analysis techniques in the study}

There is also a need to study these multi-factorial and complex phenomena using a powerful analyzing technique. As both sexuality and psychological health are complex, and have a complex relationship, they should be examined by implementation of a powerful data analyzing method such as data mining.

\section{Conclusion}

Sexual instinct is known as one of the basic needs of human beings. Sexuality is an inseparable part of human's life and is influenced by many factors. Mental health is also a complex phenomenon, necessary for both healthy living and success.

It is becoming increasingly important to identify different factors affecting relationships between sexuality and mental health in individuals, and understanding their individual and integrated effect. Advanced data analysis techniques such as data mining have the power to make data analysis process more efficient and effective, and generate knowledge that will increase our understanding of these related phenomena.

We hope that new knowledge derived with the help of cutting-edge computer technologies such as data mining will be useful in sexual counseling, sexual education, and psychological clinics.

\section{Acknowledgment}

This research has been carried out whilst Marjan Khajehei has been a Curtin International Research Scholar in Australia.

\section{References}

[1] "World Health Organization (WHO) Definition of sexual health", 2004.

2] "Diagnostic and Statistical Manual of Mental Disorders-IV-TR. Washington, DC:American Psychiatric Association", 2003.

[3] R. Rosen, "Prevalence and risk factors of sexual dysfunction in men and women", Current Psychiatry Reports, 2000, pp. 189195.

[4] J. Smit, L. Myer, K. Middelkoop, S. Seedat, R. Wood, L. Bekker, "Mental health and sexual risk behaviours in a South African township: A community-based cross-sectional study", Public Health, 2006, pp. 534-542.

[5] J. T. F. Lau, X. Yang, Q. Wang, Y. Cheng, H.Y. Tsui, L.W.H. Mui, "Gender power and marital relationship as predictors of sexual dysfunction and sexual satisfaction among young married couples in rural China: A population-based study", Urology, 2006, pp. 579-585.

[6] N. C. C. Vulink, D. Denys, L. Bus, L; H.M.G. Westenberg, "Sexual pleasure in women with obsessive-compulsive disorder", Journal of Affective Disorders, 2006, pp. 19-25.

[7] S. Davison, R.J. Bell, M. LaChina, S.L. Holden, S.R. Davis, "The Relationship between Self-Reported Sexual Satisfaction and General Well-Being in Women", Journal of Sexual Medicine, 2009, pp. 2690-2697.

[8] A. Danaci, S. Oruç, H. Adigüzel, Y. Yildirim, O. Aydemir, "Relationship of sexuality with psychological and hormonal features in the menopausal period", West Indian Medical Journal, 2003, pp. 27-30.

[9] R. Nappi, F. Albani, V. Valentino, F. Polatti, L. Chiovato, A.R. Genazzani, "Aging and sexuality in women", Minerva Ginecology, 2007, pp. 287-298.

[10] A. Borissova, R. Kovatcheva, A. Shinkov, M. Vukov, "A study of the psychological status and sexuality in middle-aged Bulgarian women: significance of the hormone replacement therapy (HRT)", Maturitas,2001, pp. 177-183.

[11] P. Frohlich, C. Meston, "Sexual functioning and self-reported depressive symptoms among college women", The Journal of Sex Research, 2002, pp. 321-325.

[12] C. Domoney, "Sexual function in women: what is normal", International Urogynecology Journal , 2009, pp. 9-17.

[13] T. Ahrold, C. Meston, "Effects of SNS activation on SSRI-induced sexual side effects differ by SSRI", Journal of Sex and Marital Therapy, 2009, pp. 311-319.

[14] A. M. Lee, L.W. Chu, C.S.Y. Chong, S.Y. Chan, S. Tam, K.S.L. Lam, "Relationship between symptoms of androgen deficiency and psychological factors and quality of life among Chinese men", International Journal of Andrology, 2009, pp. 1-9.

A. Al-Hunayan, M. Al-Mutar, E.O. Kehinde, L. Thalib, M. Al-Ghorory, "The prevalence and predictors of erectile dysfunction in men with newly diagnosed with type 2 diabetes mellitus", 
British Journal of Urology International, 2007, pp. 130-134.

[16] N. Masumori, T. Tsukamoto, Y. Kumamoto, L.A. Panser, T. Rhodes, C.J. Girman, "Decline of sexual function with age in japanese men compared with american men: results of two community-based studies", Urology, 1999, pp. 335-344.

[17] R. Shabsigh, L.T. Klein, S. Seidman, S.A. Kaplan, B.J. Lehrhoff, J.S. Ritter, "Increased incidence of depressive symptoms in men with erectile dysfunction", Urology, 1998, pp. 848852.

[18] S. Kennedy, S. Rizvi, "Sexual dysfunction, depression, and the impact of antidepressants", Journal of Clinicial Psychopharmacol, 2009, pp. 157-64.

[19] I. Turkistani, "Sexual dysfunction in Saudi depressed male patients", International Journal of Psychiatry in Clinical Practice, 2004, pp. 101-107.

[20] M. Flood, C. Hamilton, "Mapping Homophobia in Australia", Australia Institute Webpaper, 2005, pp. 1-15.

[21] M. King, E. McKeown, J. Warner, A. Ramsay, K. Johnson, C. Cort, "Mental health and quality of life of gay men and lesbians in England and Wales: controlled, cross-sectional study", British Journal of Psychiatry, 2003, pp. 552-558.

[22] K. Wright, "Researching Internet-Based Populations: Advantages and Disadvantages of Online Survey Research, Online Questionnaire Authoring Software Packages, and Web Survey Services", Journal of ComputerMediated Communication, 2005, Article No. 11.

[23] S. Russel, K. Joyner, "Adolescent sexual orientation and suicide risk: evidence from a national study", American Journal of Public Health, 2001, pp. 1276-1281.

[24] C. E. Kaestle, C.T. Halpern, W.C. Miller, C.A. Ford, "Young Age at First Sexual Intercourse and Sexually Transmitted Infections in Adolescents and Young Adults", American Journal of Epidemiology, 2005, pp. 774-780.

[25] D. Delen, G. Walker, A. Kadam, "Predicting breast cancer survivability: a comparison of three data mining methods", Artificial Intelligence in Medicine, 2005, pp. 113-127.

[26] D. Coulter, A. Bate, R.H.B. Meyboom, M. Lindquist, B.I.R. Edwards, "Antipsychotic drugs and heart muscle disorder in international pharmacovigilance: data mining study", British Medical Journal, 2001, pp. 1207-1209. 